\title{
O Pacto nacional pela Alfabetização na Idade Certa DESENVOLVIDO NA REDE MUNICIPAL DE ENSINO DE CORUMBÁ-MS (2013 -2018): AVANÇOS E DESAFIOS
}

\author{
The NAtional PACT For Literacy at the Right Age in CoRUmba \\ MUNICIPAL EDUCATION NETWORK (2013-2018): ADVANCES AND CHALLENGES
}

Flávia Miguel Ribeiro Mestre em Educação pela Universidade Federal de Mato Grosso do Sul - UFMS, Campus do Pantanal (CPAN). Prefeitura Municipal de Corumbá - PMC. Corumbá, MS - Brasil. flaviaribeirofmr@gmail.com

\author{
Marcia Regina do Nascimento Sambugari \\ Doutora em Educação pela Pontifícia Universidade Católica de São Paulo - PUC-SP. \\ Universidade Federal de Mato Grosso do Sul - UFMS. \\ Corumbá, MS - Brasil. \\ marcia.sambugari@ufms.br
}

\begin{abstract}
Resumo: $\mathrm{O}$ artigo apresenta uma pesquisa referente ao modo como ocorreu o Pacto Nacional pela Alfabetização na Idade Certa (PNAIC) na Rede Municipal de Ensino de Corumbá, Mato Grosso do Sul, no período de 2013 a 2018. Numa abordagem qualitativa, a produção dos dados deu-se por meio de estudo de relatórios pertencentes à Secretaria Municipal de Educação de Corumbá (SEMED) e de entrevista feita com duas coordenadoras responsáveis pela realização do PNAIC no Município. Verificou-se, como aspecto positivo, a preocupação voltada para a teoria e a prática de reflexibilidade (prática/teoria/prática) na construção da identidade profissional. Contatou-se também que o PNAIC não impactou totalmente a prática dos profissionais, mas contribuiu para uma mudança significativa no fazer pedagógico, apontando, portanto, a necessidade de pensar na formação continuada de professores alfabetizadores a fim de que sejam consideradas as situações problemáticas, respeitando as especificidades locais e oportunizando a ocorrência de forma contínua.
\end{abstract}

Palavras-chave: formação continuada; alfabetização; PNAIC.

Abstract: The article presents the research that investigated how the National Agreement for Literacy in the Middle Ages, known as PNAIC, occurred in the municipal school system of Corumbá, MS from 2013 to 2018. Data were produced through documentary research based on analysis of reports from the Municipal Secretary of Education (Semed) of Corumbá, from 2013 to 2018, according to the PNAIC completion. In order to complement the information, an interview was conducted with two coordinators responsible for carrying out the program in the municipality. As a positive aspect, the concern focused on the theory and practice of reflection (practice/ theory/ practice) was noticed in the construction of professional identity. It was also found that the PNAIC coordinators, it was made clear that the program did not fully impact the practices of professionals, but contributed to a significant change in pedagogical performance, pointing to the need of thinking about ongoing trainings for literacy teachers which consider the problematic situations, respect local specificities and occur continuously.

Keywords: continuing education; literacy; PNAIC.

Para citar - ABNT NBR 6023:2018

RIBEIRO, Flávia Miguel; SAMBUGARI, Marcia Regina do Nascimento. O pacto nacional pela alfabetização na idade certa desenvolvido na rede municipal de ensino de Corumbá-MS (2013 -2018): avanços e desafios. Cadernos de Pós-graduação, São Paulo, v. 20, n. 1, p. 242-252, jan./jun. 2021. Disponível em: https://doi.org/10.5585/cpg.v20n1.18467. 
Introdução

Apresentamos, neste texto, parte da pesquisa ${ }^{1}$ que investigou de que modo o Pacto Nacional pela Alfabetização na Idade Certa (PNAIC) se efetivou na Rede Municipal de Ensino de Corumbá-MS, no período de 2013 a 2018, buscando verificar os avanços e desafios postos para a formação e atuação de professores dos três primeiros anos das Séries Iniciais do Ensino Fundamental. Para tanto, elencamos, como finalidade específica, analisar os relatórios desse Programa, elaborados pela Secretaria Municipal de Educação (SEMED).

Para Furghestti, Greco e Cardoso (2012), historicamente, a educação brasileira vem arrastando, ao longo do tempo, desafios ainda não superados: altas taxas de evasão e repetência; problemas na formação, na carreira e na valorização de professores; infraestrutura inadequada e a contradição entre acesso e sucesso escolar, já que o ingresso nas escolas brasileiras não tem representado a apropriação do processo de alfabetização, sendo esse um dos maiores impasses para a tão almejada qualidade no ensino. Contudo, as autoras ressaltam que a temática alfabetização tem sido alvo de debate nos campos educacional e político no Brasil, desde o início do século XXI, com a implantação de programas de formação continuada direcionados aos professores alfabetizadores, a fim de garantir formação àqueles que atuam com crianças as quais estão no período da aprendizagem em questão.

Cruz e Martiniak (2018) assinalam que são décadas de investimento em formação continuada, retomando, desde 2001, o Programa de Formação de Professores Alfabetizadores (PROFA). A constituição da Rede Nacional de Formação Continuada de Professores da Educação Básica em 2004, tendo o Pró-Letramento como uma de suas ações de formação, ocorrido entre o período de 2008 a 2012, em parceria com algumas universidades, foi considerado pelo governo federal como experiência exitosa ao melhorar os resultados educacionais observados a partir do Índice de Desenvolvimento da Educação Básica (IDEB) e da Prova Brasil, levando o programa a ser referência para a constituição do Pacto Nacional pela Alfabetização na Idade Certa (PNAIC), em 2013.

Com a intenção de atingir os objetivos propostos, utilizamos a abordagem qualitativa, por meio da pesquisa documental, a partir da análise de relatórios pertinentes à SEMED/Corumbá, de 2013 a 2018, referentes à realização do PNAIC. Essa etapa contou com o termo de autorização da SEMED para que pudéssemos ter acesso aos documentos.

Conforme apontam Prodanov e Freitas (2013, p. 55), esse procedimento difere da pesquisa bibliográfica, pois, “[...] a pesquisa documental baseia-se em materiais que não receberam ainda um tratamento analítico ou que podem ser reelaborados de acordo com os objetivos da pesquisa". 
Para organizarmos e analisarmos os dados, fizemos uma exploração dos materiais cedidos pela SEMED/Corumbá, dividindo-os em duas etapas: a primeira com os relatórios físicos colocados à nossa disposição pela coordenadora local, responsável pelas ações do programa entre o período de 2013 a 2016 e os documentos no formato digital, disponibilizados pela coordenadora local, encarregada pelos anos de 2017 e 2018.

Posteriormente, realizamos uma leitura fluente dos relatórios que continham anexos, tais como cronogramas, textos, propostas de atividades, materiais de divulgação e os relatos das ações desenvolvidas com breves históricos, entre outros. Os documentos foram organizados numa sequência cronológica para dar continuidade à análise, durante a qual buscamos agrupar as informações de cada ano referentes à quantidade de formadores responsáveis, ao número de participantes, à carga horária, aos materiais disponíveis, ao conteúdo trabalhado e à avaliação das atividades desenvolvidas.

A fim de complementar os dados, fizemos entrevistas com as pessoas responsáveis pelo PNAIC em Corumbá, no período de 2013 a 2018, mais especificamente as que atuaram no perfil de coordenador local, definidas como Coordenadora Local A (responsável entre os anos de 2013 a 2016) e Coordenadora Local B (responsável pela coordenação de 2017 e 2018).

Este estudo contou com a utilização de um roteiro semiestruturado e as participantes assinaram o Termo de Consentimento Livre e Esclarecido (TCLE), assegurando-as do sigilo das informações pessoais, conforme determinam as normas do Comitê de Ética para pesquisa com seres humanos.

Tal ação teve como foco captar a percepção de cada entrevistada em relação ao programa, elencando os pontos positivos e as possíveis críticas acerca de todo o período de desenvolvimento do PNAIC em Corumbá.

O texto está organizado em duas partes, a primeira apresenta uma breve contextualização do Programa no cenário nacional e a segunda discute como ocorreu a implantação do PNAIC em Corumbá no período de 2013 a 2018, apontando os aspectos positivos, bem como os limites.

Com este estudo buscamos contribuir para as políticas públicas da Educação, no sentido de suscitar discussões e reflexões, englobando os profissionais dos três primeiros anos do Ensino Fundamental, na interface com a formação continuada.

\section{Situando o PNAIC no cenário nacional}

O PNAIC foi instituído por meio da Portaria no 867 de 4 de julho de 2012 (BRASIL, 2012), com apoio técnico e financeiro do governo federal, conforme estabelecido na Lei n. 12.801, de 24/04/2013 (BRASIL, 2013): 
Art. 1 Esta Lei dispõe sobre o apoio técnico e financeiro da União aos entes federados no âmbito do Pacto Nacional pela Alfabetização na Idade Certa, com a finalidade de promover a alfabetização dos estudantes até os 8 (oito) anos de idade ao final do $3^{\circ}$ ano do ensino fundamental da educação básica pública, aferida por avaliações periódicas.

Os professores do ciclo de alfabetização eram o público-alvo da formação do PNAIC e o seu foco, a prática pedagógica desses profissionais. Um dos objetivos do programa consistiu em trazer uma ampla reflexão teórica sobre a alfabetização e os caminhos para a utilização em sala de aula, de jogos pedagógicos, fundamentações e reflexões sobre os conceitos de alfabetização e letramento, currículo, rotina, planejamento, ludicidade, literatura e o ensino da Língua Portuguesa na alfabetização (BRASIL, 2013).

Outro objetivo do PNAIC consistiu em assegurar a alfabetização de crianças dos três primeiros anos do Ensino Fundamental, ou seja, até os oito anos de idade, em contrapartida aos baixos índices de alfabetização apresentados pelos indicadores de qualidade e ainda, tendo como ação principal, a formação continuada de professores alfabetizadores, com a finalidade de superar o desafio em busca da tão almejada qualidade do ensino, especificamente, no Ensino Fundamental.

Em 2013, o PNAIC baseou-se na formação em Língua Portuguesa e, em 2014, na formação em Matemática. Em 2015, a novidade foi a ampliação para as demais áreas do conhecimento, de forma integrada, abrangendo a educação integral das crianças nesse início do processo de escolarização. Para a nova etapa da formação, cada orientador de estudos e professor alfabetizador recebeu um kit de formação contendo um caderno de apresentação, um caderno para gestores e equipe pedagógica e dez cadernos com textos teóricos sobre os temas da formação, relatos de professores e sugestões de atividades (BRASIL, 2015).

A fim de buscar uma educação de qualidade, na qual as crianças não apenas aprendam a ler e a escrever mas também saibam interpretar textos e fazer contas, as ações do PNAIC apoiaramse em quatro eixos de atuação, quais sejam:

- Formação continuada presencial de professores alfabetizadores: é uma tarefa complexa que envolve o esforço conjunto de diferentes segmentos da sociedade. O programa do Ministério da Educação desenvolve-se em parceria com Universidades Públicas Brasileiras e Secretarias de Educação Estadual/Municipal. O Pacto abrange os professores que atuam nas turmas dos três primeiros anos do ciclo de alfabetização.

Para Nascimento et al (2015, p. 42.497), o sistema de formação do PNAIC apresenta a seguinte estrutura: 
[...] uma proposta de formação em cascata ou pirâmide: os formadores das universidades formam aos formadores regionais, que voltam às suas regiões e formam os orientadores de estudo, os quais compartilham a formação com os professores alfabetizadores. Os momentos são pensados para unir teoria e prática de forma que as duas se complementem. Esse modelo formativo é eficiente, em especial considerando-se o fator tempo, pois se chega a várias regiões do país de maneira rápida e quase simultânea. Outra vantagem é auxiliar no fortalecimento das lideranças regionais e locais, colaborando para a consolidação da excelência do trabalho das Secretarias de Educação.

- Materiais didáticos, literatura e tecnologias educacionais: são formados por conjuntos de materiais específicos para apoio à alfabetização, tais como livros didáticos, dicionários de Língua Portuguesa, jogos pedagógicos, obras de literatura, obras de apoio pedagógico aos professores e tecnologias de apoio.

- Avaliação: três componentes principais envolvem de forma sistemática: avaliações processuais (podem ser desenvolvidas e realizadas pelo alfabetizador e seus alunos); a Provinha Brasil, que será aplicada de forma organizada no início e no final do $2^{\circ}$ ano. Aos alunos do $3^{\circ}$ ano, haverá uma avaliação universal externa, pelo Instituto Nacional de Estudos e Pesquisas Anísio Teixeira (INEP) para aferir o nível de alfabetização alcançado no final do ciclo por meio da ANA. Ainda segundo os documentos, a avaliação é importante para a garantia da aprendizagem, uma vez que os planejamentos podem ser redefinidos conforme as necessidades apresentadas por essa ferramenta.

Considerando que a avaliação é parte constituinte do processo pedagógico e que, com base nela, é possível entender melhor quais são os conhecimentos das crianças e suas dificuldades, podem ser desenvolvidas estratégias diversas em sala de aula em que as crianças sejam atendidas de formas diferenciadas (BRASIL, 2015, p. 35).

- Gestão, mobilização e controle social: é a forma pela qual se propõe a efetivar as metas de alfabetização de todas as crianças (no máximo até oito anos) com o envolvimento e a mobilização social, no sentido de ter uma gestão eficiente com todos os atores envolvidos: poder público, sociedade civil e comunidade escolar.

Conforme consta no documento de apresentação do PNAIC, “[...] estar alfabetizado significa ser capaz de interagir por meio de textos escritos em diferentes situações, significa ler e produzir textos para atender a diferentes propósitos" (BRASIL, 2015, p. 19). Com o intuito de atingir esse objetivo, faz-se necessário que os professores estejam preparados e motivados a acompanharem o processo de aprendizagem das crianças.

Outro ponto importante proposto pelo PNAIC refere-se aos materiais didáticos e pedagógicos apropriados e que estimulem o aprendizado. Entendendo não ser suficiente somente dispor dos materiais, mas saber manuseá-los e extrair dos conteúdos o máximo de disponibilidades para dinamizar e alcançar os objetivos da alfabetização em cada ano. 
O PNAIC no contexto da Rede Municipal de Ensino de Corumbá-MS (2013-2018)

Foi implementado na Rede Municipal de Ensino, ano de 2013, pela SEMED/Corumbá, o PNAIC, que “[...] tornou-se um dos programas mais estratégicos do município de Corumbá para assegurar que todos os alunos estejam alfabetizados até os oito anos de idade, ou seja, ao final do $3^{\circ}$ ano do Ensino Fundamental” (RELATÓRIO, 2016, p.12). Com referência à implantação do PNAIC na REME de Corumbá, a coordenadora local A relatou-nos que:

\footnotetext{
Reunimos todos os gestores, explicamos o que era o projeto juntamente com os coordenadores, aí tinham as séries selecionadas de $1^{\circ}$ ao $3^{\circ}$ ano. Já vinha uma agenda montada de Campo Grande, poderíamos fazer as adaptações. Eu quero até enaltecer e ressaltar a questão da organização do PNAIC no seu inicio com a Universidade Federal, era extremamente organizada, a agenda tanto as que se cumpriam lá como você trazia pra cá extremamente organizado, todos os passos. Um material riquíssimo, textos variados, vídeos, todos esses materiais, a gente recebia num CD e trazia para multiplicar no municipio. [...] nós percebemos que a implantação do PNAIC trouxe para as salas de aulas de alfabetização o cantinho da leitura, aquela questão de se trabalhar com o visual para a criança ter apoio, então foi assim nesse sentido, com o apoio de todas as escolas (Coordenadora local A. Entrevista).
}

Podemos verificar, por meio da análise dos relatórios fornecidos e da entrevista com a coordenadora local A, que, no início do Programa, havia uma preocupação com o calendário das atividades, os prazos eram respeitados. As formações eram realizadas nas escolas, de forma intercalada e em espaços externos. Com o intuito de o Programa prosperar, havia, semanalmente, reunião entre os orientadores de estudos e a coordenadora local para traçarem o planejamento das ações. Eram efetivadas visitas nas escolas, acompanhamento dos professores em sala e da coordenação, além da verificação de como estavam sendo utilizados os materiais didáticos disponibilizados.

No período de 2013 a 2016, muitas ações foram executadas, conforme nos mostrou o relatório. Iniciaram com os materiais disponibilizados nos kits contendo os cadernos orientadores. As propostas foram apresentadas, na perspectiva do letramento, através de palestras, seminários e discussão das atividades propostas, destacando a importância do planejamento dessas ações, da organização do trabalho, da previsão do tempo pedagógico e da construção de rotinas no sentido de promover o atendimento e a formação das crianças em alfabetização.

No ano de 2014, houve a primeira ampliação do Programa, agora com ênfase em Matemática, também identificamos, nesse período, a preocupação dos responsáveis com a qualidade da formação e a necessidade do replanejamento de algumas ações no sentido de valorizar os conhecimentos e questionamentos trazidos pelos professores. Entre os temas trabalhados, existiu a preocupação com a importância da teoria a qual apresentasse uma prática de reflexibilidade (prática/teoria/prática) e com a construção da identidade do professor. O relatório também traz a 
consciência de que o Programa não impacta totalmente na prática dos profissionais, mas eles conseguem perceber uma mudança significativa no fazer pedagógico.

As ações de 2015 trouxeram pontos importantes devido à ampliação do Programa para as demais áreas do conhecimento, no contexto de formação integral da criança. Foram abordados temas necessários para o desenvolvimento da prática pedagógica como a atividade da reflexibilidade, trabalhando prática/teoria/prática, destacando a importância de um referencial teórico e a construção da identidade profissional. A formação pautou-se no professor como sujeito da ação e detentor do processo de mudança de sua formação, compartilhando experiências, as dificuldades e os acertos. Nesse sentido, Imbernón (2010) destaca algumas estratégias que devem ser utilizadas na metodologia da formação continuada, para romper com o individualismo da profissão docente:

[...] A colaboração é um processo que pode ajudar a entender a complexidade do trabalho educativo e a dar respostas melhores às situações problemáticas da prática. [...] entender a educação que busca propiciar espaços onde se dê o desenvolvimento de habilidades individuais e grupais de troca e de diálogo, a partir da análise e da discussão entre todos no momento de explorar novos conceitos. Tudo para que cada um conheça, compartilhe e amplie as metas de ensino e a informação que possui sobre um tema. Cada um dos membros do grupo é responsável tanto por sua aprendizagem quanto pela dos outros. Os professores compartilham a interação e a troca de ideias e conhecimentos entre os membros do grupo (IMBERNÓN, 2010, p. 65).

Em 2016, houve uma ampliação do público-alvo da formação, estendendo-se aos coordenadores escolares, e dos estudos direcionados ao conceito de avaliação, análise dos critérios da Avaliação Nacional da Alfabetização. Nesse contexto, as discussões foram voltadas para as estratégias de intervenção mediante ao resultado das avaliações, percebendo, assim, a ligação direta entre os resultados e as ações do Programa.

Outro ponto a ser destacado nos relatórios de 2013 a 2016 refere-se à sensibilidade em rever algumas ações e a compreensão dos limites do Programa. Em resposta a essa percepção, foram criados espaços na formação para que os profissionais pudessem relatar suas experiências e dificuldades como também compartilhar seus conhecimentos. Socializando o conhecimento, vemos essa ação de forma muito positiva.

As ações do PNAIC, em 2017, trouxeram a ampliação do Programa para a Educação Infantil e o Programa Novo Mais Educação. Nessa época, ocorreu uma descaracterização em relação à proposta inicial, excluindo a responsabilidade das universidades nas formações dos professores, transferindo para as Secretarias de Estado de Educação com o intuito de oferecer mais "liberdade" para as secretarias no sentido de "flexibilizar" as ações, conforme a realidade local. Dois impactos significativos foram sentidos: o primeiro, no fornecimento dos materiais, 
principalmente, dos livros complementares; o segundo, em relação à concessão de bolsas que foram direcionadas para cargos específicos e não se estendendo aos professores cursistas.

Mesmo com todas as mudanças, podemos perceber, pelos dados analisados, que houve avanços positivos na prática pedagógica dos professores e a intenção de continuar com a proposta inicial do Programa, porém sem sucesso.

As descontinuidades das políticas públicas estão diretamente relacionadas à troca de governos, não há uma gestão e nem uma agenda brasileira a qual trate o tema com a atenção merecida, uma vez que acarreta desperdícios de recursos públicos e os resultados se tornam ineficazes. Podemos perceber esses fatos quando há interrupções de trabalhos já iniciados, com mudanças na prioridade, passando a prevalecer o viés político-partidário. O Pnaic não foi exceção, pois a educação pública de qualidade não é prioridade.

Em razão do afastamento da presidenta Dilma Rouseff e a ascensão do presidente Michel Temer, em 31 de agosto de 2016, as ações do programa, em 2017, sofreram profundas mudanças as quais desfiguraram os principais eixos que o fundamentaram. Com uma crise econômica em curso, houve a redução de investimentos. Isso tornou clara a queda da qualidade e a fragilidade com a qual se encerrou o Programa em 2018, deixando de fornecer os materiais didáticos, um dos recursos essenciais que subsidiaram as ações pedagógicas dos professores, informação confirmada pelos relatos das coordenadoras e das pesquisadoras, sempre citados como uma importante ferramenta que norteava os trabalhos dos professores e a concessão das bolsas de estudos aos professores cursistas.

Ao analisarmos os documentos do PNAIC 2017 realizado em Corumbá em todo seu contexto, podemos perceber a descontinuidade de ações que foram muito relevantes nos anos anteriores, consideradas como pontos fortes na avaliação do Programa, tais como: fornecimentos de materiais didáticos, participação da universidade nas formações, bolsa de estudos, planejamento das ações e o cumprimento do calendário anual.

Fica evidenciada, nos materiais de web conferência e textos disponibilizados, a intenção de associar a aprendizagem com questões neurocientíficas.

Em relação ao impacto na formação dos professores, a coordenadora local B sinalizou o seguinte:

Os professores cursistas que acompanharam as formações do PNAIC desde o inicio, quando organizado pelas universidades, até o último módulo de formação em 2018 ofertado pela Secretaria de Estado de Educação, sentiram diferenças na dinâmica dos estudos. Contudo, ainda foi possivel verificar o aperfeiçoamento na prática dos professores com base nos estudos e trocas de experiências nos encontros de formação. Observou-se que houve a retomada do brincar como meio ideal para a alfabetização no ciclo do $1^{\circ}$ ao $3^{\circ}$ ano do Ensino Fundamental (Coordenadora local B. Entrevista). 
Quanto aos avanços, ela comentou a informação abaixo:

Conforme diagnóstico da Avaliação municipal por meio da Ação Educativa foi possivel perceber melhoria na leitura e produção textual dos alunos que cursaram o $3^{\circ}$ ano em 2017, avaliados em 2018 (Coordenadora local B. Entrevista).

Sobre a sua percepção acerca do Pacto, ela destaca o que se segue:

Na etapa final do Programa observei que o mesmo sofreu muitas alterações, descaracterização. Houve tentativa, por parte das coordenações locais e formadoras locais, em manter o Programa com o foco inicial, mas infelizmente não foi possivel em sua integra (Coordenadora local B. Entrevista).

Com a análise dos dados, percebemos que as ações referentes ao PNAIC no período de 2017 a 2018 foram as que mais sentiram os efeitos da falta de continuidade devido às mudanças nas políticas educacionais e ainda à ampliação do programa.

O Município de Corumbá-MS apresenta, na zona rural, muitas especificidades, que são trabalhadas de forma distinta pela SEMED. As escolas são separadas em dois seguimentos: escolas rurais de assentamentos e escolas rurais das águas.

Pelo fato de a cidade estar situada dentro do complexo do Pantanal e possuir uma grande extensão territorial, as escolas das águas são localizadas nas regiões ribeirinhas chegando a ter, aproximadamente, 400 quilômetros de distância da cidade.

Podemos verificar, nos documentos analisados, limitações referentes a esse público, principalmente, porque o PNAIC é um programa realizado em nível nacional. Sem trabalhar as especificidades locais, o programa teve pouca efetividade em relação às escolas rurais, mesmo tendo evidenciando contribuições nas práticas pedagógicas das professoras.

Existe, nesse contexto, uma complexidade muito grande, não somente em observar as características locais mas também o perfil dos professores alfabetizadores que vão à zona rural de Corumbá-MS, pois a rotatividade de educador nessas áreas se dá também pela desistência dessas pessoas por não se adaptarem à dinâmica do trabalho. Por conta de todas essas diversidades apresentadas, observa-se que se faz necessária uma política de formação específica aos profissionais de educação os quais desempenham sua função no campo, favorecendo ações contextualizadas com a realidade local.

A pesquisa também identificou pontos em comum nos materiais analisados: a falta de continuidade do professor alfabetizador após as formações. Nem todos continuam nos primeiros anos das Séries Iniciais, isso devido à grande quantidade de educadores contratados pela Rede Municipal. A substituição chega a ocorrer, ocasionalmente, duas vezes por ano devido ao fato de o contrato de trabalho ser divido em duas etapas, primeiro e segundo semestre. Essa rotatividade prejudica o desenvolvimento das ações, pois, teoricamente, o novo profissional partirá do "zero" em relação ao conhecimento do Programa e o contexto dos alunos. 
Essa problemática da quebra de vínculo do professor alfabetizador com a turma e também com os Anos Iniciais, uma vez que tal educador não volta a atuar na alfabetização no ano seguinte, apresentada no programa em Corumbá-MS, afeta diretamente a qualidade do ensino oferecido, pois a aprendizagem é um processo complexo e precisa ter as suas etapas respeitadas.

Com a troca de professores no meio do ano, a dificuldade aumenta significativamente, já que o profissional terá de ambientar-se, traçar novamente o perfil da turma e isso demanda tempo. Não sendo efetivo e não permanecendo nos Anos Iniciais, temos um ciclo vicioso que reflete, diretamente, na qualidade do ensino, o que faz com que o resultado das políticas públicas para a melhoria da educação seja prejudicado.

\section{Considerações finais}

Com a realização desse estudo fica evidente que, apesar dos avanços em relação à formação continuada para professores alfabetizadores, historicamente, o Brasil não tem políticas educacionais contínuas. Essa interrupção também foi sentida pelas coordenadoras locais. O conhecimento perde-se entre um programa e outro, porque cada proposta parte do pressuposto que a formação deve ter uma "nova roupagem" não considerando os conhecimentos adquiridos nas formações anteriores ou com foco diferenciado.

Diante de todos os problemas enfrentados e das limitações do PNAIC, podemos considerar que foram muitas as contribuições as quais se efetivaram nas práticas pedagógicas dos professores alfabetizadores, na percepção, principalmente da coordenadora local A e na análise dos relatórios. O profissional passou a ter outro olhar e a entender-se como sujeito da ação, percebendo a necessidade de discutir suas práticas e compartilhar suas experiências em uma profissão considerada solitária, individual. Segundo Imbernón (2010, p. 64) "[...] a formação de professores pode ajudar a romper com a cultura individualista, já que a formação coletiva supõe uma atitude constante de diálogo, de debate, de consenso [...]”.

À vista das evidências levantadas, consideramos alguns pontos que poderão contribuir para novas políticas educacionais, alguns expostos exaustivamente, tanto nos relatórios, quanto nas entrevistas. Destacamos, portanto, como uma das limitações do PNAIC, a ausência de uma política que parta da problematização, respeitando as especificidades locais; uma formação específica para os professores do campo e a rotatividade dos professores alfabetizadores nos primeiros anos das Séries Iniciais. Acreditamos que esses são pontos os quais se devem repensar ao avaliar a proposição de política pública efetiva que, de fato, garanta o direito à educação. 
${ }^{1}$ Esta pesquisa contou com o apoio da Universidade Federal de Mato Grosso do Sul (UFMS) e da Coordenação de Aperfeiçoamento de Pessoal de Nível Superior - Brasil (CAPES) Código de Financiamento 001.

\section{Referências}

BRASIL. Lei n. 12.801, de 24 de abril de 2013. Dispõe sobre o apoio técnico e financeiro da União aos entes federados no âmbito do Pacto Nacional pela Alfabetização na Idade Certa e altera as Leis n. 5.537, de 21 de novembro de 1968 e n. 8.405, de 9 de janeiro de 1992, e 10.260, de 12 de julho de 2001. Diário Oficial da União [da] República Federativa do BRASIL. Poder legislativo: Brasília, DF, 25.04.2013, retificado em 26.04.2013, seção 1, 2013. Disponível em: http://www.planalto.gov.br/ccivil_03/_Ato2011-2014/2013/Lei/L12801.htm Acesso em 30 dez. 2019.

BRASIL. Portaria n. 867, de 4 de julho de 2012. Institui o Pacto Nacional pela Alfabetização na Idade Certa e as ações do Pacto e define suas diretrizes gerais. Diário Oficial da União [da] República Federativa do Brasil. Poder legislativo: Brasília, DF, 05.07.2012, n. 129, seção 1, p. 22-23, 2012. Disponível em:

http://www.lex.com.br/legis_23490618_PORTARIA_N_867_DE_4_DE_JULHO_DE_2012.a spx Acesso em 30 dez. 2019.

BRASIL. Secretaria de Educação Básica. Diretoria de Apoio à Gestão Educacional. Pacto Nacional pela Alfabetização na Idade Certa. Interdisciplinaridade no ciclo de alfabetização. Caderno de Apresentação. Brasília: MEC, SEB, 2015. Disponível em: http://pacto.mec.gov.br/materiaislistagem/item/download/21_9945a2941359afb9a5bc726869f697c5. Acesso em 30 dez. 2019.

CRUZ, M. M. P.; MARTINIAK, V. L. O ensino da leitura e sua relação com a formação de alfabetizadores: apontamentos a partir da produção acadêmica. Práxis Educativa. Ponta Grossa, v. 13, n. 1, p. 67-84, jan./abr. 2018. Disponível em

http://www.revistas2.uepg.br/index.php/praxiseducativa/article/view/10681/6149 Acesso em 30 dez. 2019.

FURGHESTTI, M. L.S; GRECO, M.T.C; CARDOSO, R.C.F. Ensino Fundamental de Nove Anos: os impactos das políticas públicas para a alfabetização com letramento. In: REUNIÃO ANUAL DA ANPED SUL, Seminário de pesquisa em educação da região sul. 09. Anais [...] Caxias do Sul, 2012, p. 1-18.

IMBERNON, F. Formação continuada de professores. 2. ed. Porto Alegre: Artmed, 2010.

NASCIMENTO, T. S.; FRANÇA, M. S. L. M.; SABÓIA, V. S. M.; GIRÃO, A. E. M. O processo de formação continuada do PNAIC: reflexões sobre a experiência. CONGRESSO NACIONAL DE EDUCAÇÃO - EDUCERE, 12, Anais [...] PUC-PR: Curitiba, p. 4249542503, 2015. Disponível em: https://educere.bruc.com.br/arquivo/pdf2015/21312_11277.pdf. Acesso em: 30 dez. 2019.

PRODANOV, C.; FREITAS, E. C. Metodologia do trabalho científico [recurso eletrônico]: métodos e técnicas da pesquisa e do trabalho acadêmico. 2.ed. Novo Hamburgo: Feevale, 2013. Disponível em: http://www.feevale.br/Comum/midias/8807f05a-14d0-4d5b-b1ad-1538f3aef538/Ebook\%20Metodologia\%20do\%20Trabalho\%20Cientifico.pdf. Acesso em: 20 fev 2019.

RELATÓRIO. Secretaria Municipal de Corumbá. Pacto 2013 a 2016. Corumbá: Semed, 2016. 